\title{
ANALISIS SALURAN DAN MARGIN PEMASARAN PUPUK BERSUBSIDI (UREA DAN NPK PHONSKA) DI KECAMATAN MALANGKE KAB. LUWU UTARA
}

\author{
Analysis Of Multi-Fertilizer (Urea And Npk Phonska) Marketing Margin In Malangke \\ District, Kab. North Luwu \\ Rahmi Azizah Mudaffar \\ Email: cicaami@gmail.com
}

Prodi Agroteknologi Fakultas Pertanian, Universitas Andi Djemma Palopo

\begin{abstract}
Abstrak
Penelitian ini bertujuan Untuk Mengetahui bentuk saluran pemasaran pupuk bersubsidi ( Urea dan Phonska) dan fungsi pemasaran yang dilakukan oleh produsen dan lembaga pemasaran di daerah penelitian dan Untuk mengetahui besarnya biaya pemasaran, Margin Pemasaran dan Shere Margin ) setiap lembaga pemasaran yang terlibat dalam saluran pemasaran?. Penelitian ini dilakukan pada bulan Agustus-Oktober 2019 di Kec. Malangke Kabupaten Luwu Utara dengan pertimbangan kecamatan ini merupakan merupakan salah satu sentra penghasil tanaman Jagung ( Tanaman Pangan). Data yang digunakan dalam penelitian ini adalah data primer dan data sekunder. Hasil penelitian menujukkan bahwa Hanya ada satu saluran pemasaran pupuk bersubsidi didaerah peneltian yaitu Produsen, Distributor, Pengecer, Petani. Produsen melakukan 4 Fungsi Pemasaran yaitu Penjualan, Penyimpanan, transportasi dan pembelian. Selain 4 funngsi pemasaran tersebut diatas, produsen juga melakukan fungsi pembelian dalam hal pegadaan bahan baku tetapi tidak melakukan pembelian hasil produksi yang berupa pupuk, sedangkan lembaga pemasaran yang yang terlibat yaitu distributor dan pengecer melakukan 5 fungsi pemasaran yaitu pembelian, penjualan, transpotasi, penyimpanan dan pembiayaan.
\end{abstract}

Kata kunci: analisis, margin pemasaran, pupuk bersubsidi

\begin{abstract}
This study aims to find out the form of subsidized fertilizer marketing channels (Urea and Phonska) and the marketing function carried out by producers and marketing institutions in the research area and To find out the amount of marketing costs, Marketing Margins and Shere Margins) of each marketing institution involved in marketing channels?. This research was conducted in August-October 2019 in Kec. Malangke, North Luwu Regency with the consideration of this district is one of the centers of producing corn (food crops). The data used in this study are primary data and secondary data. The results showed that there was only one marketing channel for subsidized fertilizer in the research area, namely the Farmer's Retail Distributor Manufacturer. Manufacturers perform 4 marketing functions, namely sales, storage, transportation and purchasing. In addition to the 4 marketing functions mentioned above, the producer also performs purchasing functions in the case of raw material procurement but does not purchase fertilizer products, while the marketing institutions involved, namely distributors and retailers, perform 5 marketing functions, namely purchasing, selling, transportation, storage and financing.
\end{abstract}

Keywords: analysis, marketing margins, subsidized fertilizer

\section{PENDAHULUAN}

Ketahanan pangan merupakan kondisi terpenuhnya pangan bagi Rumah Tangga yang tercermin dari ketersediaan pangan yang cukup baik jumlah maupun mutunya, aman, merata dan terjangkau (Purwono dan Heni. P, 2007). Dalam rangka mewujudkan ketahanan pangan nasional, pemerintah berupaya untuk meningkatkan produktivitas dan kulalitas hasil pertanian melalui penerapan teknologi budidaya secara tepat dengan penggunaan sarana produksi sesuai teknologi yang direkomendasikan di 
masing-masing wilayah. Sarana produksi mempunyai peranan sangat penting dalam peningkatan produktivitas dan kualitas hasil pertanian sasalah satunya adalah pupuk. Efektivitas penggunaan Pupuk diarahkan pada penerapan pemupukan berimbang sesuai rekomendasi spesifik lokasi atau standar teknis penggunaan pupuk yang dianjurkan.

Pupuk telah senantiasa berada dilini depan dalam usaha untuk meningkatkan produksi pangan dunia dan mungkin leih dari pada jenis yang lain. Dengan memasok hara tanah yang esensial bagi produksi tanaman yang tinggi, pupuk telah menjadi vital untuk produksi tanaman.

Pupuk merupakan salah satu sarana produksi yang memiliki peranan penting dalam peningkatan produksi dan kualitas hasil budidaya tanaman. Melihat begitu besarnya peranan pupuk dalam peningkatan produktivitas dan produksi komoditi pertanian untuk mewujudkan ketahanan pangan nasional maka pmerintah mengeluarkan peraturan Menteri Pertanian Republik Indonesia Nomor 87/Permentan／SR.301/12/2011 tentang kebutuhan harga eceran tertinggi (HET) Pupuk Bersubsidi untuk sektor pertanian tahun anggaran 2012. Dalam peraturan tersebut pemerintah mensubsidi sejumlah pupuk yang direkomendasikan dari setiap daerah untuk disediakan dan menetapkan harga eceran tertinggi (HET) 243
Pupuk bersubsidi meliputi pupuk Urea, ZA, SP-36, NPK dan Organik melalui produsen pupuk yang ditunjuk oleh pemerintah. Harga Eceran Tertinggi (HET) tersebut mulai diberlakukan sejak tanggal 1 januari 2012. Jenis pupuk yang mengalami perubahan harga dari HET sebelumnya yakni pupuk urea yang mengalami kenaikan sebesar $12,5 \%$.

Sistem distribusi pupuk bersubsidi dilakukan dengan sistem rayonisasi sehingga berpotensi terjadi distorsi . Selama ini Departemen Perdagangan berwenang menentukan tata niaga pupuk tentang penyaluran dan rayonisasi pemasaran pupuk bersubsidi dengan tujuan menjaga kepastian harga, kebutuhan, serta wilayah pemasaran pupuk bersubsidi. Namun sistem rayonisasi ini juga dapat menimbulkan jalur birokrasi yang rumit, apabila terdapat daerah yang mengalami kekurangan pasokan pupuk tidak dapat langsung ditangani oleh produsen/ distributor lain, dikarenakan pupuk merupakan barang dalam pengawasan negara. Dalam pengalihan lokasi pupuk bersubsidi ke lain daerah pemasaran yang ditentukan pemerinyah dapat terjerat pidana

Pengadaan dan penyaluran pupuk bersubsidi dari produsen (Lini I dan Lini II) menggunakan jalur distribusi melalui distributor (Lini III) dan penyalur atau pengecer resmi. Di Kec. Malangke 
terdapat beberapa Pengecer pupuk bersubsidi yang tersebar di 14 desa di wilayah Kecamatan Malangke. Ada Beberapa Permasalahan yang dihadapi dalam pengadaan pupuk. Antar lain masalah harga, pemasaran, permodalan pedagang dan petani. Dalam hal ini masalah pemasaran merupakan masalah yang penting, karena dalam pemasaran ini melingkupi berbagai masalah seperti harga, tataniaga, kelangkaan pupuk dan sebagainya.

Berdasarkan uraian di atas dari gambaran pentingnya pupuk dalam peningkatan produksi dan produktivitas pertanian serta permasalahan dalam pendistribusian pupuk bersubsidi maka peneliti mengambil judul "Analisis Saluran dan Margin Pemasaran Pupuk Bersubsidi (Urea dan NPK Phonska) di Kecamatan Malangke Kab. Luwu Utara “ penelitian ini bertujuan Untuk Mengetahui bentuk saluran pemasaran pupuk bersubsidi ( Urea dan Phonska) dan fungsi pemasaran yang dilakukan oleh produsen dan lembaga pemasaran di daerah penelitian, Untuk mengetahui besarnya biaya pemasaran, Margin Pemasaran dan Shere Margin ) setiap lembaga pemasaran yang terlibat dalam saluran pemasaran?

\section{METODE PENELITIAN Waktu dan Tempat}

Penelitian ini dilakukan pada bulan
Agustus -Oktober 2019 di Kec. Malangke Kabupaten Luwu Utara dengan pertimbangan kecamatan ini merupakan merupakan salah satu sentra penghasil tanaman Jagung ( Tanaman Pangan).

\section{Populasi dan Sampel}

Populasi adalah semua lembaga pemasaran yang terlibat dalam pemasaran pupuk bersubsidi. Dalam penelitian ini pengambilan responden dilakukan dengan menggunakan metode saturation sampling ( sampling jenuh ), istilah lain dari metode ini adalah metode sensus.

\section{Jenis dan Sumber Data}

Data yang digunakan dalam penelitian ini adalah data primer dan data sekunder, dapat dijelaskan sebagai berikut:

1. Data primer merupakan data yang didapat dari sumber pertama baik dari individu atau perseorangan seperti hasil wawancara atau hasil pengisian kuesioner yang biasa dilakukan peneliti. Data primer yang diperoleh dalam penelitian ini dilakukan dengan wawancara secara langsung dengan responden antara lain unit niaga produsen, distributor, pengecer dan petani yang menggunakan pupuk Urea dan NPK Phonska.

2. Data sekunder diperoleh dari instansi-instansi yang berkaitan dengan penelitian ini.

Data yang dimaksud adalah data yang 
didapat dari Badan Pusat Statistik, kantor camat tempat penelitian ataupun dari sumber data lainnya.

\section{Analisis Data}

Apabila peneliti bermaksud mengetahui sesuatu mengenai apa dan bagaimana, berapa banyak, sejauh mana dan sebagainya, maka penelitiannya bersifat deskriptif, yaitu menjelaskan atau menerangkan peristiwa.

Alat analisis yang digunakan adalah analisis deskriptif, yaitu berusaha untuk menggambarkan atau melukiskan suatu keadaan, atau subyek dan objek penelitian yang berdasarkan fakta-fakta yang ada. Oleh karena itu metode yang digunakan adalah metode deskriptif.

Data yang diperoleh dari lapangan akan ditabulasi dengan alat uji yang sesuai yaitu:

1) Untuk menjawab identifikasi masalah (1) diuji dengan analisa deskriptif berdasarkan survey di daerah penelitian.

2) Untuk menjawab identifikasi masalah (2)

- mengenai biaya pemasaran dihitung dengan menjumlahkan seluruh biaya yang dikeluarkan selama menjalankan fungsi-fungsi pemasaran oleh masing-masing lembaga pemasaran

- Untuk menghitung margin pemasaran di gunakan rumus:
$\mathrm{Mji}=\mathrm{Psi}-\mathrm{Pbi}$ atau

$\mathrm{Mji}=\mathrm{bti}+\mathrm{i}$

Keterangan:

$\mathrm{Mji}=$ Margin pada lembaga pemasaran tingkat ke-i

Psi = Harga jual pada pemasaran tingkat ke-i

Pbi = Harga beli pada pemasaran tingkat ke-i

Bti = Biaya pemasaran tingkat ke-i

I $=$ Keuntungan pemasaran tingkat ke-i

- Untuk menghitung Share margin pada identifikasi masalah digunakan rumus:

$$
\mathrm{Sm}=\frac{P P}{P K} X 100 \%
$$

Dimana: $\mathrm{Sm}=$ Persentase Margin dihitung dalam persen

Pp = Harga yang diterima produsen dan pedagang

$\mathrm{Pk}=$ Harga yang dibayar

oleh konsumen akhir

\section{HASIL DAN PEMBAHASAN \\ Deskripsi Responden 1 Unit Niaga Produsen Pupuk}

Unit niaga produsen merupakan perpanjangan dari produsen yang merupakan tempat penyimpanan barang produsen di kabupaten. Produsen adalah perusahaan yang memproduksi pupuk Urea dan NPK Phonska. Produsen dalam penelitian ini ada dua perusahaan yaitu 
PT. Kalimanatan Timur sebagai produsen Urea yang berada di Bontang dan PT. Petrokimia Gresik, Jawa Timur. Produsen mengirim pupuk ke setiap Propinsi sesuai dengan jumlah permintaan dari setiap daerah yang aka dibagikan kepada setiap distributor yang bertanggung jawab di kabupaten /kotamadya di propinsi tersebut.

\section{Distributor Pupuk}

Distributor yang menjadi responden adalah distributor yang bertanggung jawab untuk kabupaten Luwu Utara, Kecamatan Malangke, Distributor ini akan menjual pupuk kepada setiap yang bertanggungjawab di Kecamatan yang telah ditetapkan, Distributor pupuk Urea adalah PT. Marina Putra Indonesia atas nama pengelola Eghi, $\mathrm{SH}$ yang beralamat dimasamba dan Distributor pupuk NPK Phonska adalah PT. Gresik Cipta Sejahtera atas nama pengelola Sudirman yang beralamat di Masamba, dengan masing-masing volume penjualan distributor pupuk permusim tanamam yaitu untuk PT. Marina Putra Indonesia sebagai distributor pupuk Urea sebesar 556 ton/musim tanam sedangkan untuk PT. Gresik Cipta Sejahtera sebagai distributor pupuk NPK Phonska yaitu sebesar 256 ton/musim tanam.

\section{Pengecer}

Pengecer yang menjadi responden dalam penelitian ini seluruh pengecer resmi pupuk Urea dan NPK Phonska yang berdomisili di Wilayah Kecamatan Malangke yang berjumlah 7 pengecer dan tersebar di 7 Desa. untuk pengecer pupuk Urea tersebar di 7 desa, Rata-rata umur pengecer pupuk UREA adalah 51,71 tahun dan pengecer pupuk NPK PHONSKA adalah 52,71 tahun. dengan masing-masing volume penjualan pengecer pupuk Urea permusim tanamam yaitu untuk 7 desa dengan penjualan 556 ton dan rata-rata penjualan/ton yaitu sebesar 185,33 ton dan masing-masing volume penjualan pengecer pupuk NPK Phonska permusim tanamam yaitu untuk 7 desa dengan penjualan 260 ton dan ratarata penjualan/ton yaitu sebesar 86,67 ton. Data tentang karakteristik pengecer pupuk bersubsidi dan volume penjualan dan pembelian pupuk Urea dan NPK Phonska di Kecamatan Malangke dapat dilihat pada Lampiran 3 dan 1.

\section{Bentuk Saluran Pemasaran Pupuk Bersubsidi}

Saluran Pemasaran pupuk bersubsidi Urea dan NPK Phonska di Kecamatan Malangke diketahui bahwa saluran pemasaran melibatkan produsen, distrbutor dan pengecer. Saluran ini sudah diatur sedemikian rupa dimana semua yang terlibat sudah ditentukan atas seizin pemerintah. Pemerintah dalam hal ini memiliki peran sebagai pensubsidi produsen pupuk sekaligus pengawas peredaran pupuk tersebut sehingga petani 
memperoleh jumlah dan harga yang sesuai dengan yang telah ditetapkan pemerintah.

Produsen Urea adalah PT. Kalimantan Timur dan Produsen pupuk NPK Phonska adalah PT. Petrokimia Gresik yang kemudian menyalurkannya ketiap propinsi melaui distributor. Distributor Urea di daerah penelitian adalah PT. Marina Putra Indonesia dan distributor pupuk NPK Phonska adalah PT. Gresik Cipta Sejahtera kemudian menyalurkannya ke tiap pengecer di Kecamatan. Lalu akhirnya pengecer yang menjual langsung kepada petani.

Berikut gambar skema saluran pemasaran pupuk bersubsidi pupuk bersubsidi pupuk Urea dan NPK Phonska didaerah penelitian.

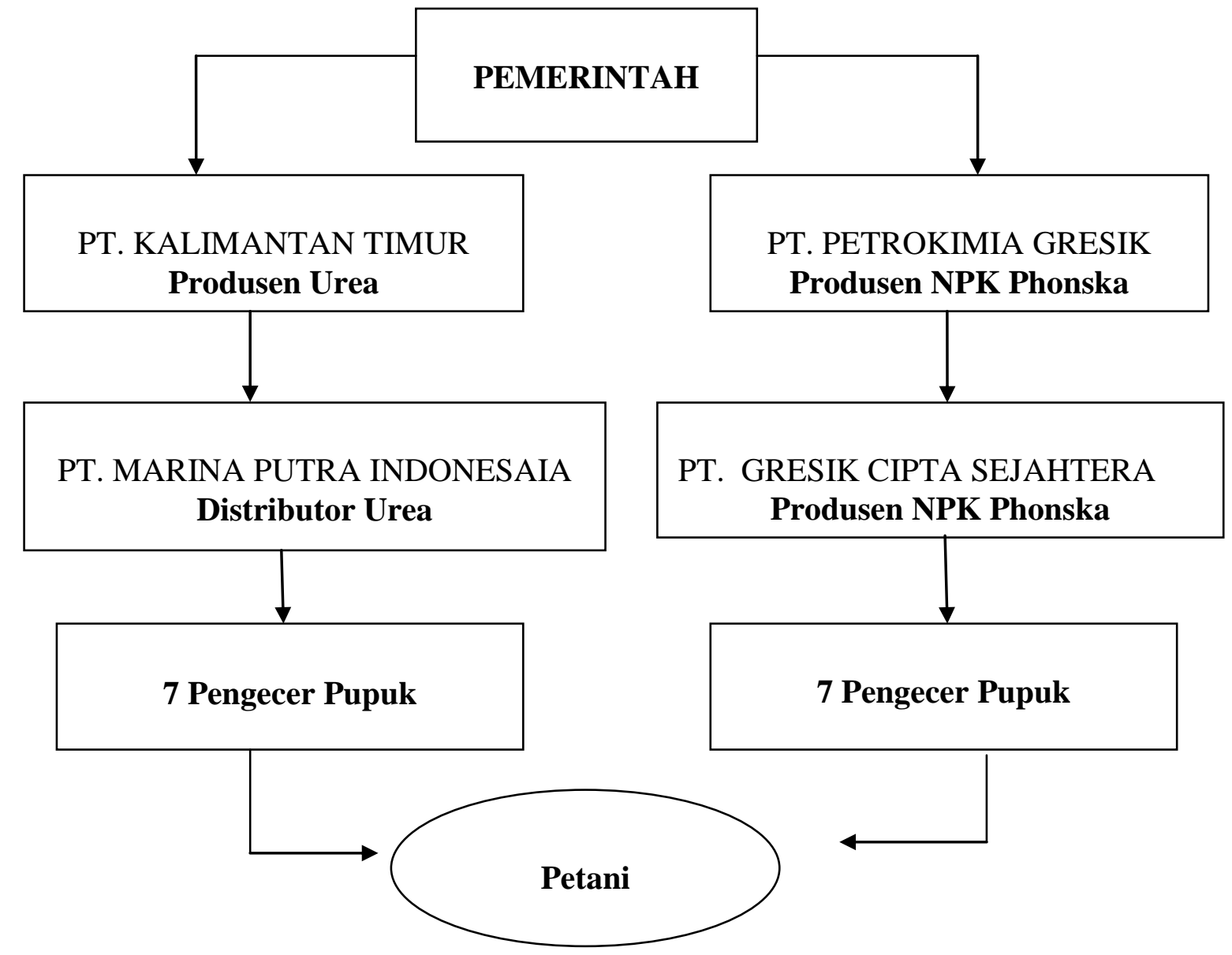

Gambar 1. Skema Saluran Pemasaran Pupuk Bersubsidi Urea dan NPK Phonska

Dapat dilihat dari skema saluran pemasaran pupuk bersubsidi bahwa penyaluran sistem distribusi pupuk saat ini diatur oleh Menteri Perdagangan. Pengaturan sistem distribusi pupuk ini dengan harapan agar petani dapat memperoleh pupuk dengan 6 azas tepat, yaitu : tempat, jenis, waktu, jumlah, mutu, dan harga. Saluran pemasaran.

Pupuk bersubsidi Urea, dan NPK Phonska pada gambar diatas melibatkan produsen sebagai perpanjangan tangan dari 
pemerintah yang dimana produsen terdiri dari PT. Kalimantan Timur Sebagai produsen Pupuk Urea dan PT. Petrokimia Gresik sebgai produsen pupuk NPK Phonska kemudian disalurkan ke distributor terdiri dari dua yakni Distributor pupuk Urea Oleh PT Marina Putra Indonesia dan PT. Gresik Cipta Sejahtera Sebagai Distributor Pupuk NPK Phonska, kemudia pada masing-masing distrtributor pupuk bersubsidi meyalurkan ke pedagang pengecer , Pedagang pengecer untuk Urea terdiri 7 pengecer sedangkan untuk pupuk NPK Phonska terdiri dari 7 pengecer kemudian petani membeli pupuk dari pengecer dengan berdasarkan Harga Eceran Tertinggi (HET).

\section{Salura Pemasaran Pupuk Urea}

Saluran pemasaran pupuk menggambarkan arus proses mengalirnya pupuk dari produsen sampai ke paetani melaui lembaga pemasaran yang terlibat. Untuk mengetahiu saluran pemasaran pupuk urea dapat dilihat pada gambar 5.2

Produsen $\longrightarrow$ Distributor $\longrightarrow$ Pengecer Kecamatan $/$ desa $\longrightarrow$ Petani

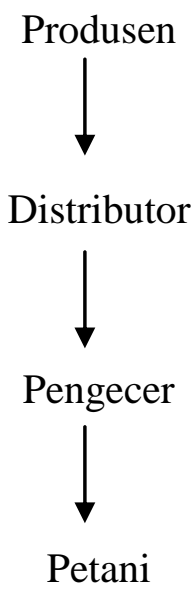

Gambar 2. Saluran Pemasaran Urea

Pada saluran ini produsen distributor yang bertanggung jawab untuk menyalurkan pupuk ke tiap propinsi kecamatan Malangke adalah PT. Putra melaui distributor dengan harga $\mathrm{Rp}$ Marina Indonesia. Pengecer resmi yang $1.595 / \mathrm{Kg}$. Adapun distributor resmi pupuk bertanggung jawab di Kecamatan urea di Kab. Luwu utara berjumlah 2 Malangke ada 7 Pengecer yaitu, Kios distributor yaitu PT. Putra Marina Awalia, Toko Rampoang Tani, Harapan Indonesia, PT. Dhanu Sumber Tani Tani Makmur, Sahabat Tani, dengan harga yang dijual kepada pengecer Megatama, Belawa Tani Sejahtera, dan yaitu sebesar Rp.1.730/Kg, sedangkan

Rejeki Bersama Tani dengan harga yang 
dijualkan kepada petani yaitu sebesar $\mathrm{Rp} .1 .800 / \mathrm{Kg}$ yaitu harga yang berlaku ditingkat pengecer dengan harga eceran tertinggi (HET)

\section{Saluran Pemasaran Pupuk NPK Phonska}

Saluran pemasaran pupuk menggambarkan arus proses menggalinya pupuk dari produsen sampai ke petani melaui lembaga pemasaran yang terlibat Untuk mengetahiu saluran pemasaran pupuk NPK Phonska dapat dilihat pada gambar 5.3

Produsen $\longrightarrow$ Distributor $\longrightarrow$ Pengecer Kecamatan /desa $\longrightarrow$ Petani

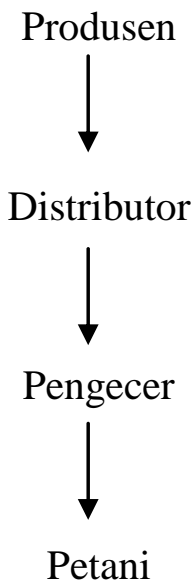

Gambar 3. Saluran Pemasaran NPK Phonska

Pada salurran ini produsen yaitu, Kios Awalia, Toko Rampoang menyalurkan pupuk ke tiap propinsi Tani, Harapan Tani Makmur, Sahabat melaui distributor dengan harga $\mathrm{Rp}$. Tani, Sahabat Tani, Megatama, Belawa 2.180/Kg. Adapun distributor resmi pupuk urea di Kab. Luwu utara berjumlah 3 distributor yaitu PT. Mega Eltra, PT. UD. Wira Tani dan PT. Gresik Citra Sjahtera sedangkan distributor yang bertanggung jawab untuk kecamatan Malangke adalah . Gresik Citra Sjahtera dengan harga yang dijulakan ke pengecer yaitu Rp.2.231/Kg. Pengecer resmi yang bertanggung jawab di Tani Sejahtera, dan Kios Tani Ladongi dengan harga yang dijualkan kepada petani yaitu sebesar Rp.2.300/Kg yaitu harga yang berlaku ditingkat pengecer dengan harga eceran tertinggi (HET)

Dari Keterangan tersebut dapat diketahui bahwa hanya terdapat 1 jenis saluran pupuk dalam pemasaran pupuk bersubsidi yaitu :

Kecamatan Malangke ada 7 Pengecer

Produsen $\longrightarrow$ Distributor $\longrightarrow$ Pengecer Konsumen

\section{Fungsi-Fungsi Pemasaran}


Fungsi pemasaran yang dilakukan oleh produsen dan lembaga-lembaga pemasaran yang akhirnya menimbulkan biaya pemasaran meliputi pembelian, penjualan, penyimpanan, transportasi dan pembiayaan. Setiap lembaga pemasaran akan melakukan fungsi pemasaran pemasaran sesuai kebutuhan lembaga itu seperti yang terlihat pada pada tabel .1 Berikut ini

Tabel 1. Fungsi-Fungsi Pemasaran yang dilakukan oleh produsen, dan Lembaga Pemasaran Pupuk Urea dan NPK Phonska.

\begin{tabular}{clccc}
\hline No & Fungsi Pemasaran & Produsen & Distributor & Pengecer \\
\hline 1 & Pembelian & $* *$ & $*$ & $*$ \\
2 & Penjualan & $*$ & $*$ & $*$ \\
3 & Penyimpanan & $*$ & $*$ & $*$ \\
4 & Transportasi & $*$ & $*$ & $*$ \\
5 & Pembiayaan & $*$ & $*$ & $*$ \\
\hline
\end{tabular}

Keterangan : ${ }^{* *}=$ Melakukan/Tidak Melakukan, $*$ Melakukan

Berdasarkan tabel diatas dapat dilihat bahwa :

a) Produsen melakukan 4 Fungsi Pemasaran, yaitu penjualan ke distributor penyimpanan pupuk sebelum pupuk dipesan distributor, biaya transportasi yang biasanya menggunakan kapal laut untuk mengantarkan pupuk ke setiap daerah, pembiayaan bongkar muat kapal, resiko hilang atau rusak serta informasi pasar yang diperoleh dari instansi pemerintah seperti Dinas Pertanian dan Dinas Perindustrian dan Perdagangan.

b) Distributor melakukukan 5 fungsi pemasaran yaitu pembelian pupuk dari produsen, penjualan pupuk kepada pengecer, penyimpanan pupuk sebelum diangkut ke pengecer, biaya transportasi, pembiayaan bongkar muat, upah tenaga kerja, air dan listruk dan sebagainya.

c) Pengecer melakukan 5 Fungsi pemasaran yaiitu pembelian dari distributor, penjualan kepada konsumen, penyimpanan pupuk selama belum dibeli konsumen, transportasi berupa pengankutan pupuk hingga ke rumah atau lokasi usaha tani dari konsumen, pembiayaan seperti upah kerja, sewa toko, air dan listrik.

\section{Besar Biaya Pemasaran, Margin Pemasaran dan Share Margin \\ Besar biaya pemasaran, margin}

Pemasaran dan Share Margin setiap lembaga pemasaran dapat dilihat pada tabel 5.2 berikut. 
Tabel 2. Biaya Pemasaran pupuk Urea dan NPK Phonska di daerah Peneltian di setiap Lembga Pemasaran $(\mathrm{Rp} / \mathrm{Kg})$

\begin{tabular}{|c|lccc}
\hline \multirow{2}{*}{ No } & \multicolumn{1}{|c|}{ Uraian } & Urea & Pupuk \\
& & 1.595 & NPK Phonska \\
\hline 1 & Harga jual produsen & 0,53 & 2.180 \\
& - Telepon & 26,97 & 0,57 \\
& - Pajak Kios & 1,88 & 0.05 \\
& - Air dan Listrik & 0,01 & 3,46 \\
& - Upah Buruh & 2,69 & 0,01 \\
& - Transport & 32,08 & 5,76 \\
& Total Biaya Distributor & & 9,85 \\
& Keuntungan Disteributor & 102,92 & 40,15 \\
2 & Herga Beli Pengecer & 1.730 & 2.231 \\
& Total Biaya Pengecer & 25,51 & 48,21 \\
& Keuntungan pengecer & 44,49 & 20,79 \\
3 & Harga Beli Konsumen & 1.800 & 2.300 \\
\hline
\end{tabular}

Sumber : Data diolah

Berdasarkan Tabel. 2 diatas diketahui biaya pemasaran yang dikeluarkan oleh distributor Pupuk :

a. Urea adalah Rp. $32,08 / \mathrm{Kg}$

b. NPK Phonska adalah Rp. $9,85 / \mathrm{Kg}$

Biaya pemasaran yang dikeluarkan oleh pengecer pupuk :

A. Urea adalah Rp. $25,51 / \mathrm{Kg}$

B. NPK Phonska adalah Rp $48,21 / \mathrm{Kg}$

Berdasarkan uraian diatas bahwa biaya pemasaran masing-masing jenis pupuk berbeda-beda di tingkat distributor dan pengecer. Biaya pemasaran yang terbesar adalah biaya yang dikeluarkan oleh Distributor pupuk NPK Phonska yaitu sebesar Rp. 48,21/Kg, Sedangkan biaya pemasaran yang terkecil adalah biaya yang dikeluarkan oleh Distributor pupuk NPK Phonska yaitu Rp. 9,85/Kg

$$
\text { Untuk mengetahui Margin }
$$
Pemasaran pada masing-masing lembaga pemasaran yang terkait dapat dihitung bilai diketahui harga jual pada pemasaran tingkat pemasaran distributor dikurang dengan harga beli pada pemasaran tingkat pengecer, dapat dilihat pada tabel.

Tabel .3 Margin pemasaran Distributor

\begin{tabular}{ccccc}
\hline No & Distributor & $\begin{array}{c}\text { Harga Beli } \\
(\mathbf{R p} / \mathbf{K g})\end{array}$ & $\begin{array}{c}\text { Harga Jual } \\
(\mathbf{R p} / \mathbf{K g}\end{array}$ & $\begin{array}{c}\text { Margin Pemasaran } \\
(\mathbf{R p} / \mathbf{K g})\end{array}$ \\
\hline 1 & Urea & 1,595 & 1.730 & 135 \\
2 & NPK & 2.180 & 2.231 & 51 \\
& PHONSKA & & & \\
\hline
\end{tabular}


Tabel 4. Margin pemasaran Pengecer

\begin{tabular}{ccccc}
\hline No & Pengecer & $\begin{array}{c}\text { Harga Beli } \\
(\mathbf{R p} / \mathbf{K g})\end{array}$ & $\begin{array}{c}\text { Harga Jual } \\
(\mathbf{R p} / \mathbf{K g}\end{array}$ & $\begin{array}{c}\text { Margin Pemasaran } \\
(\mathbf{R p} / \mathbf{K g})\end{array}$ \\
\hline 1 & Urea & 1.730 & 1800 & 70 \\
2 & NPK & 2.231 & 2.300 & 69 \\
\hline
\end{tabular}

Berdasarkan Tabel 4. diatas margin pemasaran pada distributor

a) Pupuk Urea adalah Sebesar

$$
\mathrm{Rp} .135 / \mathrm{Kg}
$$

b) Pupuk NPK Phonska Sebesar Rp.51/Kg

Bersarkan Tabel diatas Margin a) Pupuk Urea adalah Sebesar Rp.70/Kg

b) Pupuk NPK Phonska Sebesar Rp.69/Kg

Untuk mengetahui sebaran harga dan Share Margin jenis pupuk Urea dan NPK Phonska dapat dilihat pada tabel .5

Pemasaran pda Pengercer

Tabel 5. Sebaran Harga dan Share Margin

5.a Pupuk Urea

\begin{tabular}{llcc}
\hline \multirow{2}{*}{ No } & \multicolumn{1}{c}{ Uraian } & $\begin{array}{c}\text { Sebaran Harga } \\
(\mathbf{R p})\end{array}$ & $\begin{array}{c}\text { Share Margin } \\
(\boldsymbol{\%})\end{array}$ \\
\hline 1 & Harga beli distributor & 1.595 & 88,61 \\
2 & Total biaya pemasaran & 57,59 & 3,20 \\
& Distributor & 32,08 & 1,78 \\
& Pengecer & 25,51 & 1,41 \\
3 & Keuntungan & & \\
& Distributor & 102,92 & 5,72 \\
& Pengecer & 44,49 & 2,48 \\
4 & Harga Beli Konsumen & 1.800 & 100 \\
\hline
\end{tabular}

Sumber : Data diolah

5.b Pupuk NPK Phonska

\begin{tabular}{llcc}
\hline \multirow{2}{*}{ No } & \multicolumn{1}{c}{ Uraian } & $\begin{array}{c}\text { Sebaran Harga } \\
(\mathbf{R p})\end{array}$ & $\begin{array}{c}\text { Share Margin } \\
(\mathbf{\%})\end{array}$ \\
\hline 1 & Harga beli distributor & 2.180 & 94,78 \\
2 & Total biaya pemasaran & 58,06 & 2,52 \\
& Distributor & 9,85 & 0,42 \\
& Pengecer & 48,21 & 2,06 \\
3 & Keuntungan & & \\
& Distributor & 40,15 & 2,23 \\
& Pengecer & 20,79 & 1,15 \\
& Harga Beli Konsumen & 2.300 & 100 \\
\hline
\end{tabular}

Sumber : Data diolah 
Berdasarkan Tabel 5.4 diatas Share Margin pada Distributor :

a) Pupuk Urea adalah $5.72 \%$

b) NPK Phonska adalah 2,23\%

Berdasarkan Tabel daiatas Share Margin pada Pengecer :

a) Pupuk Urea adalah 2,48 \%

b) Pupuk NPK Phonska 1,15\%

Berdasarkan uraian di atas, Share Margin terbesar berada pada Distributor pupuk urea yakni 5,72\%, Sedangkan Share Margin yang terkecil berada pada pupuk Urea Yakni 2,48\%, sedangkan Share Margin terkecil berada pada pengecer pupuk NPK Phonska yaitu sebesar 1,15\% .

\subsection{Keuntungan Bersih Distributor} dan pengecer

Keuntungan bersih distributor dan pengecer dapat dihitung bila diketahui berapa besar Fee ( bayaran) yang diterimah oleh masing masing lembaga pemasaran tersebut. Fee (bayaran) diterima oleh distributor pupuk Urea adalah sebesar Rp.135/kg NPK Phonska adalah sebesar Rp.51/Kg. Fee (bayaran) yang diterima oleh pengecer sebesar pupuk Urea adalah sebesar Rp.70 /Kg dan Fee (bayaran) Untuk NPK Phonska adalah Sebesar Rp. 69/Kg. Fee (bayaran) yang diterima oleh distributor lebih besar dibanding Fee yang diterima pengecer, karena distributor masih menanggung biaya transportasi sedangkan pengecer tidak menanggung biaya transportasi. Keuntungan bersih lebaga pemasaran dapat dihitung dengan cara: Fee dikurangi total biaya pemasaran kemudian dikalikan dengan volume penjualan secara matematikadapat dihitung dengan cara:

\section{Keuntungan Bersih $=($ Fee-Total Biaya Pemasaran) x Total Volume Penjualan}

Volume penjualan distributor pupuk Urea dan NPK Phonska keuntungan selama penelitian ini dapat dilihat pada tabel 6.

Tabel 6. Volume penjualan Distributor Pupuk Urea dan NPK Phonska dan keuntungan Bersih

\begin{tabular}{cccccc}
\hline $\begin{array}{c}\text { N } \\
\text { o }\end{array}$ & Distributor & $\begin{array}{c}\text { Total Volume } \\
\text { Penjualan }(\mathbf{K g})\end{array}$ & $\begin{array}{c}\text { Fee } \\
(\mathbf{R p})\end{array}$ & $\begin{array}{c}\text { Total Biaya } \\
\text { Pemasaran } \\
(\mathbf{R p})\end{array}$ & $\begin{array}{c}\text { Keuntungan } \\
\text { Bersih } \\
(\mathbf{R p})\end{array}$ \\
\hline 1 & Urea & 556.000 & 135 & 32.08 & 57.223 .520 \\
2 & NPK & 260.000 & 51 & 9,85 & 10.699 .000 \\
& PHONSKA & & & & \\
\hline
\end{tabular}

Sumber: Data diolah

Dari Tabel 6. diatas dapat dilihat 57.223.520 dan distributor pupuk NPK bahwa keuntungan Distributor Urea Rp.

Phonska adalah sebesar Rp. 10.699.000. 
Keuntungan bersih pengecer pupuk Urea da NPK Phonska secara keseluruhan Sebesar Rp.32.083.910.

\section{KESIMPULAN}

Dari hasil penelitian saluran pemasaran pupuk Bersubsidi didaerah penelitian diperoleh beberapa kesimpulan yaiitu :

1. a. Hanya ada satu saluran pemasaran pupuk bersubsidi didaerah peneltian yaitu Produsen, Distributor, Pengecer, Petani.

b. Produsen melakukan 4 Fungsi Pemasaran yaitu Penjualan, Penyimpanan, transportasi dan pembelian. Selain 4 funngsi pemasaran tersebut diatas, produsen juga melakukan fungsi pembelian dalam hal pegadaan bahan baku tetapi tidak melakukan pembelian hasil produksi yang berupa pupuk, sedangkan lembaga pemasaran yang yang terlibat yaitu distributor dan pengecer melakukan 5 fungsi pemasaran yaitu pembelian, penjualan, transpotasi,penyimpanan dan pembiayaan.

2. Besarnya biaya pemasaran yang dikeluarkan oleh distributor pupuk Urea sebesar Rp.32,08/Kg dan NPK Phonska Rp.9,85/Kg. Besarnya biaya pemasaran yang dikeluarkan untuk pengecer pupuk Urea sebesar Rp.25,51/Kg dan NPK Phonska Rp.48,21/Kg. Share Margin pada distributor pupuk Urea sebesar 5,72 $\%$ dan NPK Phonska sebesar 2,23\%, Share Margin pada pengecer pupuk Urea sebesar $2,48 \%$ dan NPK Phonska sebesar $1,15 \%$.

\section{DAFTAR PUSTAKA}

Badan Litbang Pertanian, 2011. Prospek dan kendala Subsidi Pupuk Langsung ke Petani. Sinar Tani. Edisi 5-11 Oktober Hal 5-8

Chandra, G., 2004. Pemasaran Global : Internasional dan Internetisasi, Edisi I. Andi, Yogyakarta

Erwin dan T. Sabrina,. 2000. Pupuk dan Pemupukan. Balai Penelitian Tembakau Deli. Medan.

Hardjanto, W. 1996. Analisis Pendapatan dan Tingkat Kesejahteraan Petani di Kecamatan Jagakarsa, Kotamadya Jakarta Selatan. Skripsi. Fakultas Perikanan, IPB. Bogor.

Jumin, H.B., 1994. Dasar-Dasar Agronomi. Raja Grafindo Persada, Jakarta.

Kotler and Armstrong., 1999. PrinsipPrinsip Pemasaran: Edisi VIII. Erlangga, Jakarta.

Mubyarto, 1986. Pengantar Ekonomi Pertanian. LP3S Jakarta. Jakarta.

Musnawar dan Effi Ismawati., 2003 Pupuk Organik Padat, Pembuatan dan Aplikasi Cet 1. Penebar Swadaya, Jakarta.

Purwono dan Heni Purnawati. 2007. Budidaya 8 Jenis Tanaman Pangan Unggul. Penebar Swadaya, Jakarta. 


\section{PANDUAN PENULISAN NASKAH}

\section{PENULIASAN NASKAH:}

$>$ Ditulis sesuai kaidah Bahasa Indonesia yang baik dan benar (kaidah EYD dan tata bahasa), dan mengikuti etika penulisan ilmiah.

> Ditulis sesuai Format Naskah Jurnal Perbal: Pertanian Berkelanjutan, diketik dengan program Microsoft Word, baris 2 spasi, font 12, huruf Times Roman

> Artikel yang ditulis meliputi hasil pemikiran dan hasil penelitian dalam bidang pertanian. Naskah diketik dengan huruf Timea New Rowan, ukuran 12 pts, dengan spasi 1,5, dicetak pada kertas kuarto maksimum 12 halaman (no. Hal kanan bawah) dengan margin top 2,5: botton 2,5: left 2,5 dan rigth $2,5 \mathrm{~cm}$, dan diserahkan dalam bentuk printout sebanyak 2 eksemplar beserta soft file. Berkas (soft file) dibuat dengan Microsoft Word.

\section{- JUDUL DAN PENULISAN}

$>$ Judul naskah tanpa sub title ditulis dengan huruf besar semua dan ditebalkan (B). Terjamahan judul dalam bahasa inggris, ditulis miring (I) dan huruf besar untuk setiap awal kata (title case), dan tidak tebal. Bila tedapat nama latin, ditebalkan (B).

$>$ Nama penulis ditulis tebal (B), lengkap tanpa gelar. Identitas semua penulis ditulis font 11 , tidak tebal, miring (I), diletakkan di bawah judul naskah, diberi catatan superskrip !), 2), dan ${ }^{3)}$ dan seterusnya, dan dilengkapi dengan alamat email penulis pertama untuk tujuan komunikasi

\section{- ABSTRACT}

$>$ Ditulis dalam bahasa inggris, miring (I), tidak tebal, font 10, dan spasi tunggal

> Memuat lebih kurang 200 kata, disusun dalam satu alinea, berisi temuan utama terpenting hasil penelitian, dilengkapi data kualitatif dan atau kuantitatif utama terkait dengan tujuan penelitian.

$>$ Key words berisi konsep utama yang dibahas, ditulis tebal (B), miring (I), dan font 11. Jumlah key words sebaiknya berjumlah 4-6 kata atau frasa.

\section{- PENDAHULUAN}

> Berisi latar belakang dilengkapi dengan bahan rujukan sebagai dasar pemikiran penelitian, dan diakhiri dengan satu alinea yang memuat tujuan penelitian.

\section{- METODE PENELITIAN}

\section{Rancangan penelitian (Researh Design)}

$>$ Memuat informasi jenis penelitian seperti experimental (pure atau quasi experiment), survey, longitudinal study, crossectional study, dan exploration study dan lainnya. Selain itu, memuat juga tahap kegiatan utama penelitian, tempat, dan waktu pelaksanaannya.

Rancangan Percobaan (Experimental Design)
> Memuat rancangan perlakuan, pengambilan contoh, jumlah parameter yang dianalisis, pengukuran, cara pengambilan data, cara penentuan populasi, dan pengambilan contoh atau responden. Diakhiri dengan satu alinea yang menjelaskan metode pengolahan dan analisis data.

\section{Bahan dan Alat}

$>$ Bahan dan alat utama yang digunakan harus jelas dilengkapi dengan spesifikasi dan sumbernya

\section{- HASIL DAN PEMBAHASAN}

> Memuat data hasil analisis yang diikuti dengan uraian penjelasan (deduksi) dan dilengkapi penyimpulan (induksi) di setiap paragraf.

$>$ Dapat memuat sub bab dan sub sub bab.

> Pada uraian naskah, tulisan kata tabel dan gambar beserta nomor diawali dengan huruf besar pada huruf pertama dan semua huruf ditebalkan (B). Namun, judul tabel dan gambar ditulis huruf besar hanya pada huruf pertama kata pertama saja, dan tidak diteblakan.

$>$ Judul tabel dan gambar satu baris diletakkan di tengah (center lign), sedang lebih dari dua baris, maka baris ke dua dan selebihnya diletakkan dibawah huruf pertama judul baris pertama.

> Informasi di dalam tabel ditulis dengan spasi tunggal, font 11, dan rata kanan (right lign). Informasi data dalam tabel dan gambar dilengkapi dengan data standar deviasinya.

> Makna notasi dalam tabel dan gambar dijelaskan di bagian bawah luar tabel atau gambar, dengan font huruf 9-10.

$>$ Letak gambar dan tabel yang diletakkan berdekatan dengan pembahasan terkait.

$>$ Pada tabel hanya terdapat dua atau lebih garis horizontal untuk judul kolom, dan satu garis penutup tabel, tidak ada garis vertical.

\section{- KESIMPULAN DAN SARAN}

$>$ Memuat kesimpulan sebagai hasil analisis induksi pembahasan hasil analisis parameter yang mengacu pada tujuan penelitian.

\section{- DAFTAR PUSTAKA}

> Daftar pustaka ditulis dengan huruf ukran font 11 dan format mendelay, yaitu tanpa nomor urut dan disusun berdasarkan abjad nama terakhir/famili penulis utama.

$>$ Penulisan nama dimulai dengan nama famili/terakhir penulis utama, diletakkan bagian awal diikuti dengan singkat huruf besar nama penulis tanpa titik. Cara tersebut berlaku bagi penulis ke dua dan selebinya.

Judul buku ditulis huruf besar pada huruf pertama setiap awal kata yang bukan kata sambung, dan ditulis miring (I). 